\title{
REFINING BACKGROUND CORRECTIONS FOR RADIOCARBON DATING OF BONE COLLAGEN AT ORAU
}

\author{
R E Wood ${ }^{1}$ C Bronk Ramsey • T F G Higham \\ Oxford Radiocarbon Accelerator Unit, Research Laboratory for Archaeology and the History of Art, University of Oxford, \\ Oxford, United Kingdom.
}

\begin{abstract}
During the laboratory pretreatment of samples for radiocarbon dating, small amounts of carbon may be added to a sample. Contamination can be incorporated at any stage: during chemical pretreatment, combustion to $\mathrm{CO}_{2}$, graphitization, or accelerator mass spectrometry (AMS) measurement. Such carbon contamination is often modern in age, and so can have an especially severe effect on samples older than $\sim 25 \mathrm{ka} \mathrm{BP}$. During the extraction of collagen from bone using the ultrafiltration protocol at the Oxford Radiocarbon Accelerator Unit (ORAU), small amounts of young carbon are added to the sample. Currently, this contamination is poorly characterized when less than $10 \mathrm{mg}$ of collagen is extracted from a bone. Demand to date small collagen samples with ${ }^{14} \mathrm{C}$ concentrations that approach the detection limit of AMS measurement has increased recently with the growing interest in, for example, directly dating Neanderthal remains and Upper Paleolithic bone artifacts. This paper aims to reduce the minimum collagen sample size required to produce a reliable date from 10 to $5 \mathrm{mg}$ by re-examining the combustion background and subsequently the pretreatment background for bone. The average of 136 measurements of directly combusted nylon suggests that $0.0007 \pm 0.001 \mathrm{mg}$ of modern carbon is added to each sample, although the distribution is positively skewed. Regression analysis of the measurements of 52 collagen samples extracted from a bone of background age results in a background of just less than 50,000 BP for bone treated at ORAU.
\end{abstract}

\section{INTRODUCTION}

The significant effect that young contaminants have on radiocarbon dates obtained on samples that fall towards the maximum age limit of the method has long been appreciated (e.g. Waterbolk 1971; Gupta and Polach 1985). The addition of just $1 \%$ modern carbon to a sample that initially contained no ${ }^{14} \mathrm{C}$ will produce an apparent age of $37 \mathrm{ka} \mathrm{BP}$. This contamination can either be derived from the deposition and storage environment or from the laboratory itself. In the last few years, a number of new techniques have been developed and adopted to more effectively remove contamination that has been incorporated into a sample before its arrival at the laboratory. However, with the increasing complexity and length of pretreatment, the potential for laboratory-derived contamination itself increases. Laboratory contamination is normally assumed to be modern in age (Vogel et al. 1987) and so it is of the utmost importance that these sources are limited and characterized to ensure that the potential of these longer and more rigorous pretreatment methods are realized.

Brown et al. (1988) found that ultrafiltration improved the quality of gelatin by selecting the larger molecules most likely to be from the collagen present in the bone. In 2000, ultrafilters with a 30-kD molecular weight cut-off were incorporated into the bone pretreatment protocol at the Oxford Radiocarbon Accelerator Unit (ORAU) (Bronk Ramsey et al. 2004a). Subsequently, they have been found to substantially increase the accuracy of dates, particularly in the case of Paleolithic-aged bone (Higham et al. 2006a; Jacobi et al. 2006). For example, a bone point from Uphill in England, typologically similar to those of the French Evolved Aurignacian industry that occurred around 32 ka BP, was originally dated in ORAU to $28,080 \pm 360 \mathrm{BP}$ (OxA-8408) using the "AG" method described below. After ultrafiltration pretreatment, the point was found to date to $31,730 \pm 250 \mathrm{BP}$ (OxA-13716) (Higham et al. 2006a). There are many other examples of similar shifts in age for bone spanning the Middle to Late Upper Paleolithic (Higham et al. 2006b; Jacobi and Higham 2008, 2009).

${ }^{1}$ Corresponding author. Email: rachel.wood@keble.ox.ac.uk.

(C) 2010 by the Arizona Board of Regents on behalf of the University of Arizona Proceedings of the 20th International Radiocarbon Conference, edited by A J T Jull RADIOCARBON, Vol 52, $\mathrm{Nr}$ 2-3, 2010, p 600-611 
Contamination in the laboratory can occur during chemical pretreatment, combustion to $\mathrm{CO}_{2}$, graphitization, or accelerator mass spectrometry (AMS) measurement. The first two, pretreatment and combustion, dominate the error term of a ${ }^{14} \mathrm{C}$ date. At ORAU, the AMS and graphitization backgrounds are monitored for each batch of samples in the AMS through the measurement of a gas produced from anthracite (Bronk Ramsey et al. 2004b). The amount of modern carbon contamination added during combustion is assessed through the measurement of a background age nylon standard. Currently, $0.0009 \pm 0.0003 \mathrm{mg}$ modern carbon is subtracted from each sample. Contamination during pretreatment is monitored for each batch of unknown samples with 2 known-age samples of similar material, size, and age as the unknowns. Ultrafiltration is the only pretreatment method used at ORAU that appears to introduce significant quantities of modern carbon. Presumably, this is due to the length of the pretreatment and the use of ultrafilters that are composed of a polyethersulfone membrane coated in a humectant glycerol, which must be removed before use. Currently, it is estimated that the treatment adds $0.025 \pm 0.008 \mathrm{mg}$ modern carbon to each sample. This estimate was based upon repeat measurements of 2 bones that produced infinite ${ }^{14} \mathrm{C}$ dates and were assumed to be beyond the ${ }^{14} \mathrm{C}$ limit, but had no independent dating evidence to confirm this (Ramsey et al. 2004a).

This paper aims to refine the ultrafiltration pretreatment background for 2 reasons. First, it aims to produce reliable date estimations when only a small quantity of collagen can be extracted from a bone. The bone pretreatment background at ORAU is currently not well characterized below $10 \mathrm{mg}$ and, as a result, a routine minimum collagen weight of $10 \mathrm{mg}$ is imposed. In some cases, samples that have fallen below this minimum weight requirement have been dated, and given a lab prefix in the form "OxA-X-" (rather than the usual "OxA-") to signify that the laboratory considers their date less reliable. In 2006, one of us (T H) obtained a grant to date a large number of bone samples dating to the European Middle to Upper Paleolithic transition using the ultrafiltration method. This transition occurred sometime between 30 and $40 \mathrm{ka} \mathrm{BP}$, a particularly challenging period for ${ }^{14} \mathrm{C}$ dating owing to the sensitivity of results to modern contaminants. Moreover, the project aims to directly date valuable items such as Neanderthal teeth and bone artifacts that require careful sampling and therefore low starting weights, so that even when collagen percent yields are greater than $1 \%$ and so thought reliable (van Klinken 1999), only 5 mg may be extracted. Second, since the initial estimation of the bone pretreatment background at ORAU, the ${ }^{14} \mathrm{C}$ age of the humectant on the ultrafilter has changed from fossil to modern. In addition, a re-assessment is made of the laboratory combustion background.

\section{MATERIALS AND METHODS}

The ultrafiltration bone pretreatment protocol (denoted by the ORAU lab code AF) and quality assurance methods followed here are described in detail in Bronk Ramsey et al. (2004a) and Brock et al. (2007). The AG method is identical, except for the exclusion of the ultrafiltration step. Briefly:

1. The bone surface is cleaned with aluminium oxide abrasive and either crushed or drilled to a powder.

2. Some $0.2-1.0 \mathrm{~g}$ of powder is sequentially treated with $\mathrm{HCl}(0.5 \mathrm{M}), \mathrm{NaOH}(0.1 \mathrm{M})$, and finally $\mathrm{HCl}(0.5 \mathrm{M})$. Samples are thoroughly rinsed with ultrapure Milli- $\mathrm{Q}^{\mathrm{TM}}$ water following each of these stages.

3. The crude collagen is gelatinized at $70^{\circ} \mathrm{C}$ for $20 \mathrm{hr}$ in $\mathrm{pH} 3$ water.

4. The solution is filtered with a $9-\mu \mathrm{m}$ polyethylene Eezi filter ${ }^{\mathrm{TM}}$, previously cleaned by ultrasonication in Milli-Q for 20 min followed by further rinsing in Milli-Q. 
5. The $<9-\mu \mathrm{m}$ fraction is transferred to a $30-\mathrm{kD}$ MWCO Vivaspin ${ }^{\mathrm{TM}} 15$ ultrafilter and centrifuged at $3000 \mathrm{rpm}$ until $1 \mathrm{~mL}$ of concentrate remains. The ultrafilter is precleaned by centrifuging twice with $10 \mathrm{~mL}$ Milli-Q, followed by ultrasonication in Milli-Q for $1 \mathrm{hr}$ and centrifuging 10 $\mathrm{mL}$ Milli-Q a further 3 times. After the third centrifuge wash, $1 \mathrm{~mL}$ of ultrapure water is used to rinse 1 ultrafilter in each batch of samples treated. This water sample is freeze-dried and the test tube thoroughly rinsed with $20 \mu \mathrm{L}$ of Milli-Q water. This water is placed on Chromosorb ${ }^{\mathrm{TM}}$ in a tin capsule to enable measurement of carbon content in a $\mathrm{CHN}$ analyzer.

Subsequently, 5-6 mg of the freeze-dried collagen is combusted in a CHN analyzer. Samples are weighed into tin capsules and dropped into a furnace at $1000^{\circ} \mathrm{C}$ in an oxygen atmosphere, where the exothermic combustion of the tin raises the temperature to $1800{ }^{\circ} \mathrm{C}$. To complete oxidation and remove sulfur, the combustion products, carried by He, are passed through beds of chromium trioxide, copper oxide, and silver wool at $1000{ }^{\circ} \mathrm{C}$. Excess oxygen is removed and nitrogen oxides are reduced in a copper-containing reduction furnace at $600{ }^{\circ} \mathrm{C}$, and water is removed in a trap containing anhydrous magnesium perchlorate. To separate $\mathrm{CO}_{2}$ and $\mathrm{N}_{2}$ prior to collection, the gas stream is passed through a column of Carbosieve ${ }^{\mathrm{TM}} 60-80$ mesh. Some $1-2 \%$ of the gas stream is bled into an isotope-ratio mass spectrometer and the remaining $\mathrm{CO}_{2}$ is collected and graphitized as described in Dee and Ramsey (2000). Two standard graphite sizes are routinely produced at ORAU, large (1.8 $\mathrm{mg}$ carbon) and small (0.8-1 mg carbon), although only the former are normally produced from collagen. Graphites are measured in a HVEE Tandetron AMS and dates are calculated as described in Ramsey et al. (2004b). The data presented here prior to correction for combustion and pretreatment have been corrected for their AMS and graphitization background. The error on this value is derived from counting statistics and will be termed the "measurement error."

To examine the combustion background, nylon standards of background age that are routinely measured to monitor this background component may be scrutinized. Since the arrival of the new AMS at ORAU in 2002, 136 nylon samples have been combusted and dated as described above. The samples combusted contained between 1 and $2.6 \mathrm{mg}$ carbon, reflecting the standard sizes of graphite targets produced in the laboratory.

Unlike charcoal and carbonate samples - the procedural blanks of which can be monitored through the measurement of graphite and marble standards, respectively - no geological material that is likely to be contaminant free and known to be beyond the measurement limit of ${ }^{14} \mathrm{C}$ exists to allow an equivalent assessment of the procedural blank of collagen. Therefore, bone must be dated. As frequently noted (e.g. Jöris et al. 2003; Higham et al. 2006a), "collagen" in most archaeological bones is susceptible to severe contamination. This may not be removed during the laboratory treatment, and so has the potential to obscure any calculation of the procedural background. While ultrafiltration routinely produces older dates than the AG method, it is difficult to prove that all contaminants are removed in every case. Therefore, ideally, the bone used to assess the laboratory background should be free from contaminants of a different ${ }^{14} \mathrm{C}$ age.

Pig (Sus scrofa) ribs found within a barrel on the Mary Rose ship, which sank in AD 1545, are used as a young bone known-age standard as part of the standard laboratory protocol. We analyzed 72 measurements of the 68 samples of collagen extracted with the AF method between March 2007 and March 2009 to examine whether or not any ancient carbon is introduced. Collagen samples ranged in size from $20-200 \mathrm{mg}$ (average $\% \mathrm{C} 44 \pm 2 ; \delta^{13} \mathrm{C}-22.0 \pm 0.3 ; \%$ yield $17 \pm 5 ; \mathrm{C}: \mathrm{N} 3.2 \pm 0.1$ ).

The left calcaneum of a bison (Bison bison) found below the Sheep Creek-Klondike tephra at Ash Bend, Alaska, was used as a blank to assess the procedural background. This tephra is dated to 
$79,500 \pm 7500 \mathrm{yr}$ BP by OSL and Fission Track ${ }^{2}$ methods (Westgate et al. 2008), and provides a minimum age for the bone. Between 2007 and 2009, 52 collagen samples ranging in size between 1.5 and $99 \mathrm{mg}$ were extracted with the AF method $\left(\% \mathrm{C} 44 \pm 2 ; \delta^{13} \mathrm{C}-19.7 \pm 0.8 ; \%\right.$ yield $6 \pm 2$; C:N $3.3 \pm 0.1$ ). An additional 4 aliquots of between 1.6 and $42 \mathrm{mg}$ have been treated with the $\mathrm{AG}$ method (average \% $43.1 \pm 0.9 ; \delta^{13} \mathrm{C}-19.6 \pm 0.1 ; \%$ yield $7 \pm 2 ; \mathrm{C}: \mathrm{N} 3.2$ ) to provide an indication of whether significant levels of young contaminants are present within the bone.

To investigate whether the background age derived from this single bison bone is generally appropriate, measurements of 2 further Alaskan bison bones, $\mathrm{P} 18801\left(n=63\right.$; average $\% \mathrm{C} 44 \pm 3 ; \delta^{13} \mathrm{C}$ $-19.7 \pm 0.4 ; \%$ yield $3 \pm 3 ; \mathrm{C}: \mathrm{N} 3.3 \pm 0.1)$ and $\mathrm{P} 18802\left(n=49 ;\right.$ average $\% \mathrm{C} 44 \pm 2 ; \delta^{13} \mathrm{C}-19.5 \pm$ $0.4 ; \%$ yield $6 \pm 3 ; \mathrm{C}: \mathrm{N} 3.3 \pm 0.1$ ), with collagen samples ranging in size between 1.5 and $100 \mathrm{mg}$ for both bones have been analyzed. All analyses are on collagen extracted with the AF method. While these bones are strongly suspected to date to beyond the limit of ${ }^{14} \mathrm{C}$, there is no independent chronology to confirm this.

\section{RESULTS AND DISCUSSION}

As previously noted, it is usually assumed that contamination added in the laboratory is likely to be modern in age (Vogel et al. 1987). It is likely that this is the case at ORAU, both in the bone pretreatment and combustion stages. During bone pretreatment, Brock et al. (2010) have shown that the most likely contaminant is the soluble ultrafilter humectant glycerol. Since March 2005, this has been post-bomb in age. Hüls et al. (2009) suggested that it is possible that the ultrafilter membrane, which is ancient in age, could also contaminate the sample, although we have no data to support this.

Measurements of collagen extracted from the pig ribs from the Mary Rose shipwreck average $315 \pm$ $32 \mathrm{BP}$ after correction with the existing method (Figure 1). This is within error of the historic date for the sinking of this vessel of AD $1545(\sim 311 \mathrm{BP})$ and so suggests that contamination from ancient carbon does not occur. These measurements also suggest that there is no gross contamination by dead carbon in the combustion stage. However, the limited range of combustion sample sizes $(2.3 \pm$ $0.2 \mathrm{mg}$ carbon) makes this a rather insensitive test for the relatively small effect such contamination would have. Contamination of $0.8 \%$, or the addition of $0.02 \mathrm{mg}$ of fossil carbon, would be required to shift the age of the samples outside their 2- $\sigma$ range. To minimize effects from the addition of dead carbon added during combustion, AMS HOXII standards are combusted to give similar yields to samples measured together in the AMS. If it is therefore assumed that only modern carbon is added in the combustion and pretreatment stage, the measured age is equivalent to the fraction of contamination added, and so $\mathrm{F}^{14} \mathrm{C}$ is linearly related to the inverse carbon content of the sample. To account for small differences in error, all samples are weighted by $\sigma^{-2}$.

It should be noted that the distribution of residuals is likely to be a positive skew than a normal distribution due to the addition of modern carbon rather than equal amounts of modern and ancient. Although not the most appropriate model, a normal distribution must be assumed to allow for the incorporation of the error term into the ${ }^{14} \mathrm{C}$ age calculation.

${ }^{2}$ OSL ages of $69 \pm 11 \mathrm{kyr} \mathrm{BP}$ and $84 \pm 9 \mathrm{kyr}$ BP were measured for the sedimentary deposits immediately above and below the Sheep Creek tephra, alongside a Fission Track age of $82 \pm 9 \mathrm{kyr}$ BP for the Dominion Creek tephra, which is found stratigraphically above the Sheep Creek tephra in the Klondike goldfields (Westgate et al. 2008). These dates were analyzed using a Bayesian model in OxCal (Bronk Ramsey 1995, 2001), with the age of the Sheep Creek tephra determined as the difference between 2 boundaries that separated 2 phases, one containing the date below this tephra and the other containing the 2 dates above. 


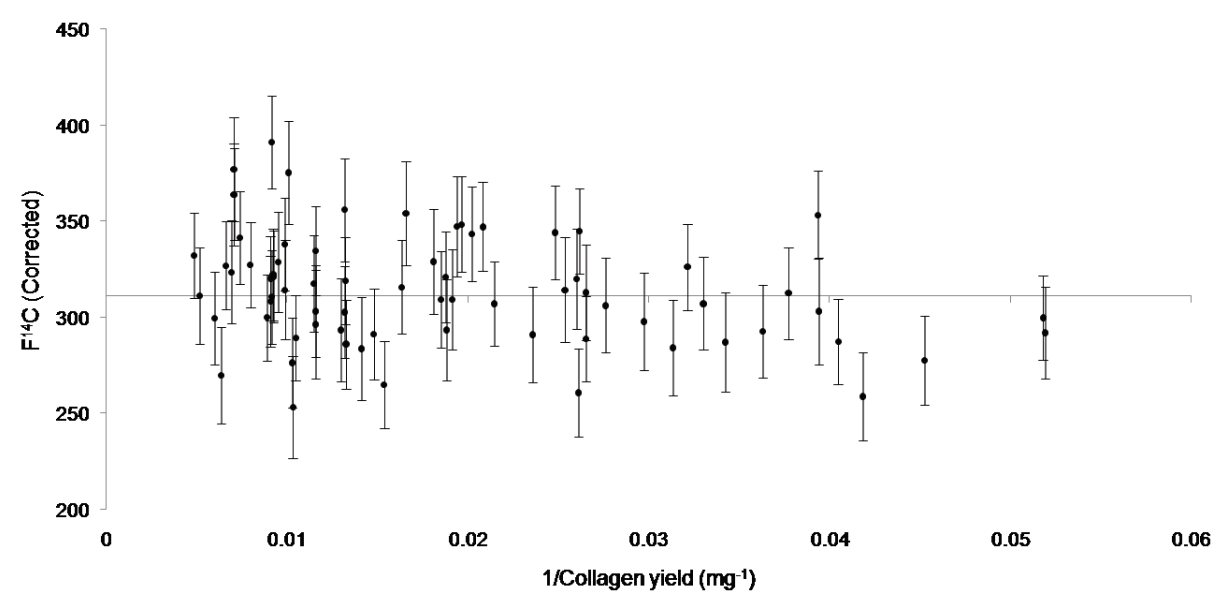

Figure 1 Measurements of pig bones from the Mary Rose after correction with the existing background correction models. The vessel sank $\sim 311 \mathrm{BP}$. Error bars are shown at $1 \sigma$.

\section{Combustion}

Nylon measurements are given in Figure 2a alongside the combustion background currently applied. Although the existing correction is of the correct magnitude, it is evident that the error term is too small and does not account for the full variation of the added modern carbon.

The data set presents 2 problems when recalculating a combustion background. First, the data set is strongly positively skewed (skewness: $1.636 \pm 0.208$ ): the majority of samples show a lower level of contamination than the average. There is no relationship between $\mathrm{F}^{14} \mathrm{C}$ and the date the sample was combusted, the equipment used, or the position of the sample within the burn to explain the youngest samples. Second, no correlation between sample size and $\mathrm{F}^{14} \mathrm{C}$ is apparent. This is unexpected (e.g. Vogel et al. 1987; Kirner et al. 1995) and may be due to the limited size range of the nylon samples used.

Despite these problems, the weighted mean and standard deviation of the mass of modern carbon added to a sample of $0.0007 \pm 0.0010 \mathrm{mg}$ will be used as a combustion background (Figure $2 \mathrm{~b}$ ). The skew means that more than $68 \%$ of corrected samples fall within 1 standard deviation of 0 , but at 2 and 3 standard deviations the model fits the data more closely (Table 1). Therefore, although the model has been forced to be normally distributed and sample size dependent where evidence exists for neither, it will be used until work currently being undertaken to date $<0.5 \mathrm{mg}$ graphite samples using the ORAU facilities is completed (Staff et al. 2009). The new correction is similar in magnitude to the existing model, but the error term is significantly larger, reducing the background age (defined as twice the standard deviation of a sample) when $1.8 \mathrm{mg}$ of carbon is combusted from 60,700 to $54,000 \mathrm{BP}$ when a typical measurement error of $0.0002 \mathrm{~F}^{14} \mathrm{C}$ is assumed.

\section{Bone Pretreatment}

Measurements of collagen extracted from the Ash Bend bone, corrected for the addition of carbon during combustion and plotted against the inverse collagen yield, are given in Figure 3a alongside the existing correction model. The largest samples are currently undercorrected, while the smallest are overcorrected. A correction based on a model that assumes no variance at an infinite mass is unrealistic and, in this case where many samples are relatively large, is problematic. The carbon content in collagen extracted from archaeological bones averages $44 \%$ (the average of the $\% \mathrm{C}$ of 


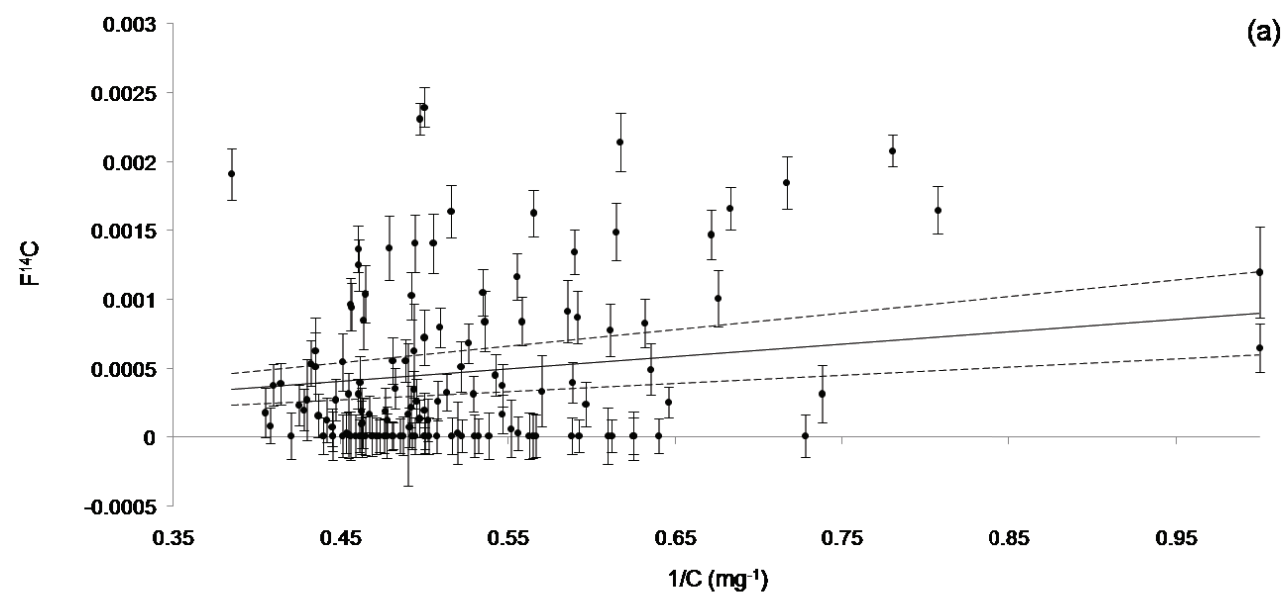

(a)

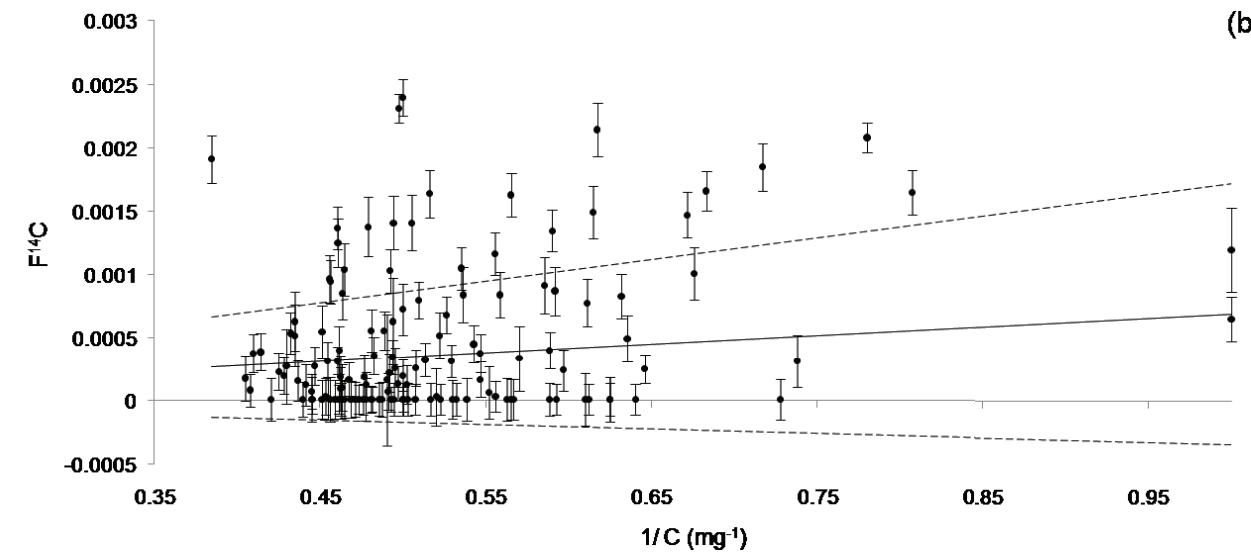

Figure 2 a) Existing combustion correction model compared to repeat measurements of nylon. b) Proposed combustion correction compared to repeat measurements of nylon. Error bars are shown at $1 \sigma$.

Table 1 Proportion of measurements of the nylon and Ash Bend bone standards lying within 1, 2, and 3 standard deviations of 0 and 2 bones close to background in age, P18801 and P18802, lying within 1,2 , and 3 standard deviations of their averages of 0.001 and $0 \mathrm{~F}^{14} \mathrm{C}$, respectively. For the bone correction, the 2 models (defined in Table 2) have been presented for comparison.

$\%$ of corrected measurements falling within $n$ standard deviations of an $\mathrm{F}^{14} \mathrm{C}$ of 0 (nylon and Ash Bend) or their weighted average (P18801 and P18802)

\begin{tabular}{lcccc}
\cline { 3 - 5 } Sample & $n$ & $1 \sigma$ & $2 \sigma$ & $3 \sigma$ \\
\hline Expected & - & $68.2 \%$ & $95.4 \%$ & $99.6 \%$ \\
\hline Nylon & 136 & $81.6 \%$ & $92.6 \%$ & $97.8 \%$ \\
\hline Ash Bend (Model 1) & 52 & $75.0 \%$ & $96.2 \%$ & $100 \%$ \\
Ash Bend (Model 2) & & $67.3 \%$ & $94.2 \%$ & $96.2 \%$ \\
\hline P18801 (Model 1) & 63 & $84.1 \%$ & $96.8 \%$ & $100 \%$ \\
P18801 (Model 2) & & $82.5 \%$ & $96.8 \%$ & $96.8 \%$ \\
\hline P18802 (Model 1) & 49 & $55.1 \%$ & $98.0 \%$ & $100 \%$ \\
P18802 (Model 2) & & $55.1 \%$ & $98.0 \%$ & $98.0 \%$ \\
\hline
\end{tabular}


1510 collagen samples OxA-dated since 2007 is $44 \pm 2.4 \%$ ). The new model will assume a carbon content of $44 \%$ and use the inverse carbon content of the collagen, rather than the collagen yield. The correlation of the repeat measurements of the Ash Bend bone against this axis is weak, but significant $(r=0.323, p=0.010$ and $F=5.608, p=0.020)$ and so a regression line has been plotted (model 1) (Table 2). The residuals are not heteroscedastic. Two points, however, must be noted:

1. When defined as more than 1.5 times the size of the interquartile range of the residuals, 2 outliers exist. These cause the distribution to be significantly skewed (skewness: $0.913 \pm 0.330$ ) and peaked (kurtosis: $2.056 \pm 0.650$ ), suggesting that the data set may not be normal and thus regression not suitable (Figure $3 \mathrm{~b}$ ).

2. The relatively low number of small samples reflects the limited number of unknown samples of this size treated within the laboratory. This uneven distribution along the $x$ axis causes a number of points to have a high leverage value. The Cook's distance, which measures the effect of deleting a given observation, demonstrates that these samples do not, however, influence the regression line more than the majority of data points because of their larger error terms (Figure $3 c)$.

To explore the effect of these outliers further, regression analysis was undertaken after their removal (model 2) and results are given in Table 2 and Figure 3d. The distribution of weighted residuals is now normal with a reduction in skewness $(0.373 \pm 0.337)$ and kurtosis $(-0.041 \pm 0.662)$. From Table 2, it is evident that removal of the outliers has little effect on the regression line parameters, but that the error term has slightly decreased. It is difficult to determine the cause of these outliers. They could be caused by inhomogeneities in the ultrafilter manufacture with, for example, some membranes containing significantly more glycerol than others. Equally, they may be caused by addition of carbon in a stage other than ultrafiltration.

To assess which model is most appropriate, the percentage of Ash Bend bone data points falling within error of an $\mathrm{F}^{14} \mathrm{C}$ of 0 was examined. In addition, the distribution of data points around the averages of 2 further bison bones, P18801 and P18802, from Alaska that are likely to be background in age was examined. Repeat measurements show these to be (or to be very close to) background in age with averages of their corrected $\mathrm{F}^{14} \mathrm{C}$ measurements within error of 0 : for both correction models, $\mathrm{P} 18801$ averages $0.001 \pm 0.001 \mathrm{~F}^{14} \mathrm{C}$ and $\mathrm{P} 18802,0 \pm 0.001 \mathrm{~F}^{14} \mathrm{C}$.

The removal of outliers does not have a large effect on the distribution of corrected measurements of P18801 or P18802. Table 1 shows that the measurements corrected by both models broadly follow a normal distribution. However, variation in the distribution of corrected measurements between the bones exceeds the variation between the 2 models. Model 2, excluding the outliers, will be used as the laboratory correction because of the marginal improvement in distribution seen at $1 \sigma$ for the Ash Bend and P18801 bones. Model 2 is plotted in Figure 3d and, after correction for the combustion background, sets a maximum background age of $49,900 \mathrm{BP}$. This only decreases significantly when samples containing $<2 \mathrm{mg}$ of carbon ( $\sim 5 \mathrm{mg}$ collagen $)$ are extracted. This is in contrast to the previous correction where the maximum background age decreased from 53,500 BP at $40 \mathrm{mg}$ collagen to 45,600 BP with $5 \mathrm{mg}$ collagen when the combustion correction suggested here is applied.

Although it is only possible to consider combustion-corrected measurements, collagen extracted from the Ash Bend bone using the AG protocol produces similar results to the AF method, suggesting that the bone is not grossly contaminated with a young carbon source and is therefore suitable for estimation of the laboratory background (Figure 4). Further support for this is given from the 


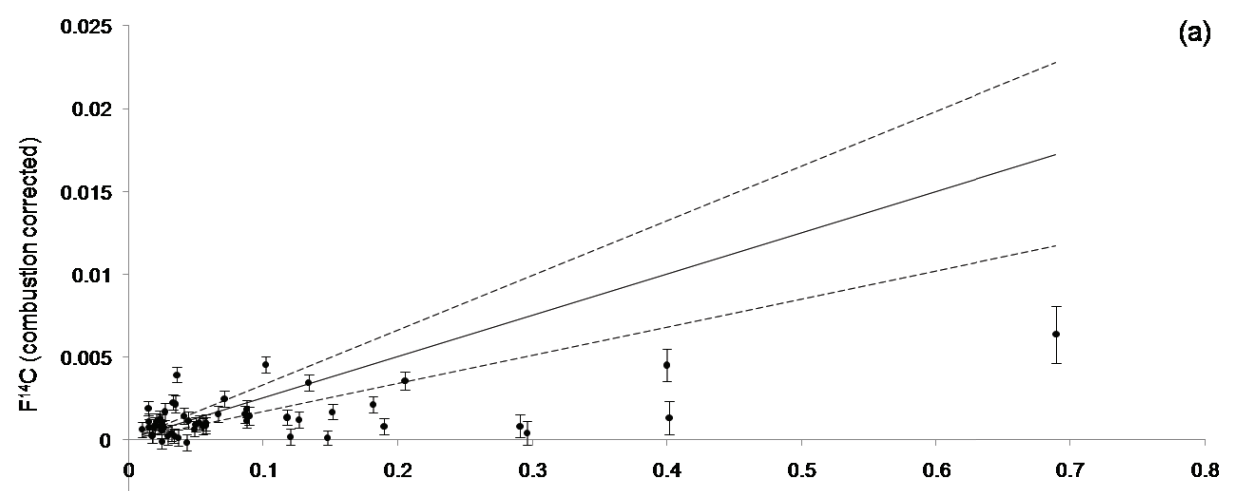

$\mathbf{- 0 . 0 0 5}$

1/Collagen yield $\left(\mathrm{mg}^{-1}\right)$
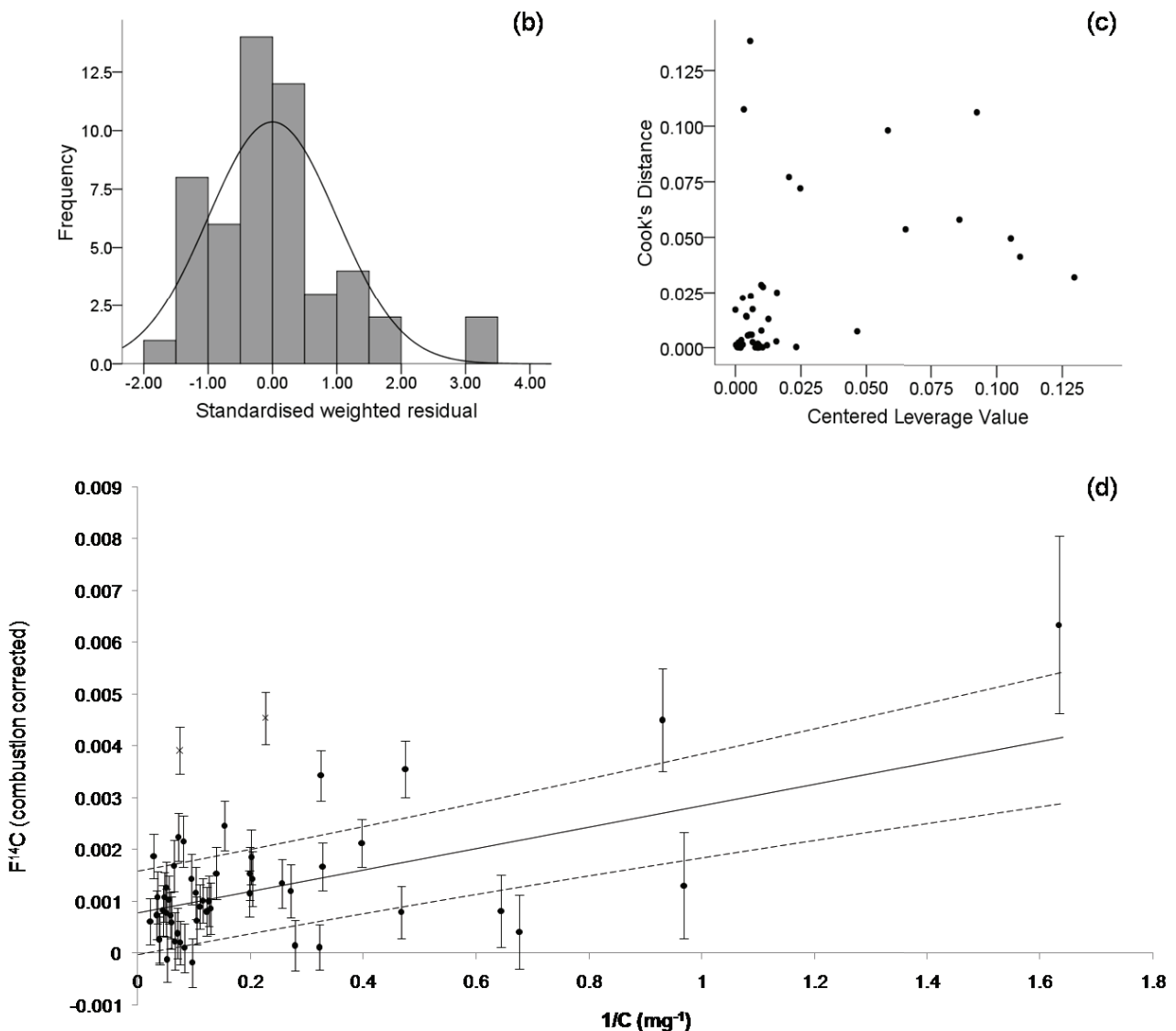

Figure 3 a) Existing pretreatment correction model applied to ultrafiltered bone, plotted with repeat measurements of the Ash Bend bone. b) A histogram of the standardized weighted residuals when all measurements are used to produce a regression line (model 1). Residuals are weighted as $\sqrt{\sigma^{-2}}$ and standardized as $\frac{(x-\mu)}{\sigma}$. The expected normal distribution using these data is superimposed. c) Cook's distance plotted against centered leverage values when all measurements of the Ash Bend bone are used to produce a regression line (model 1), calculated within SPSS Statistics 17.0. d) The proposed new pretreatment correction model against measurements of the Ash Bend bone (model 2). The 2 outliers not included in the calculation of the regression line are drawn with crosses. All error bars are shown at $1 \sigma$. 
Table 2 Comparison of the correlation and regression lines between combustion-corrected $\mathrm{F}^{14} \mathrm{C}$ and inverse carbon content of the extracted collagen for the 2 models. The first includes all data points while the second disregards 2 outliers. Maximum background ages are calculated as twice the standard deviation of the error which includes a typical measurement error term of $0.0002 \mathrm{~F}^{14} \mathrm{C}$.

\begin{tabular}{|c|c|c|c|c|c|c|c|}
\hline Model & Data set & Slope & Intercept & $r$ & $F$ & $n$ & $\begin{array}{l}\text { Maximum back- } \\
\text { ground age (BP) }\end{array}$ \\
\hline Model 1 & All samples & $0.002 \pm 0.0007$ & $0.001 \pm 0.001$ & $\begin{array}{l}0.323 \\
(p=0.010)\end{array}$ & $\begin{array}{l}5.608 \\
(p=0.020)\end{array}$ & 52 & 48,800 \\
\hline Model 2 & $\begin{array}{l}\text { Outliers } \\
\text { excluded }\end{array}$ & $0.0021 \pm 0.0006$ & $0.0008 \pm 0.0008$ & $\begin{array}{l}0.408 \\
(p=0.002)\end{array}$ & $\begin{array}{l}9.569 \\
(p=0.003)\end{array}$ & 50 & 49,900 \\
\hline
\end{tabular}

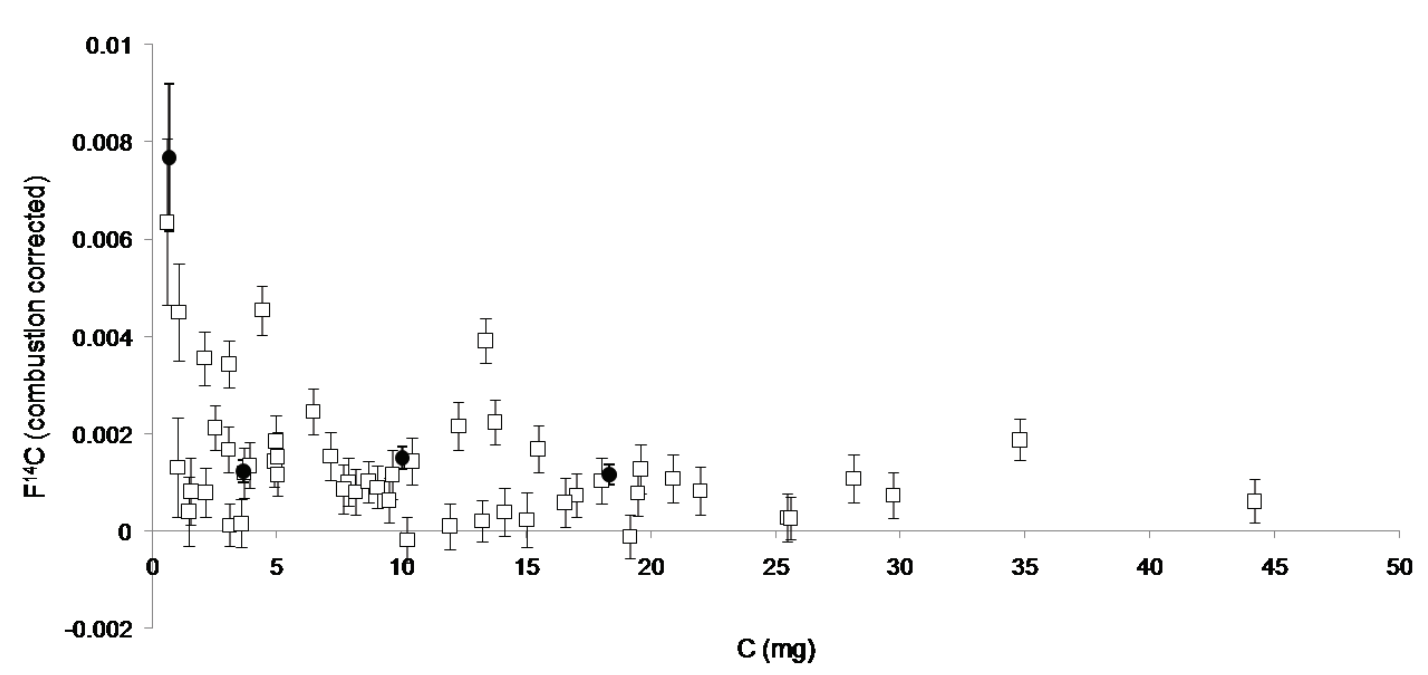

Figure 4 Comparison of AG (circles) and AF (squares) measurements of the Ash Bend bone, corrected for the combustion background using the correction proposed in this paper, and plotted against the carbon content of the collagen extracted. Error bars are shown at $1 \sigma$.

regression line that passes through the origin within error (Figure 3d) and so no young carbon exists in a sample of infinite mass. If small quantities of young contaminants do remain within the collagen after the AG treatment, they are fully removed during ultrafiltration.

It is difficult to assess whether the variation in sample age increases as the sample size decreases, as is sometimes found (e.g. Tisnérat-Laborde et al. 2003; de Rooij et al. 2008) because few samples were treated below $2 \mathrm{mg}$ carbon (or $\sim 5 \mathrm{mg}$ collagen). Therefore, only samples above $2 \mathrm{mg}$ carbon are regarded as reliable, and any sample falling below this weight will be ascribed an OxA-X- laboratory code to denote the lower reliability of the background subtraction.

Figures $5 \mathrm{a}$ and $\mathrm{b}$ compare the effect that the previous and new corrections have for large and small collagen samples, respectively. There is little difference between the corrections for dates younger than $25 \mathrm{ka} \mathrm{BP}$. However, beyond this, the error is increased for large collagen yields, while for small samples the magnitude of the correction is reduced and the precision improved. The most significant impact in changing the correction is the measurement of the point at which the samples become infinite in age. Table 3 shows various ${ }^{14} \mathrm{C}$ dates obtained within the Middle-Upper Palaeolithic Project mentioned earlier and demonstrates that only the oldest and smallest samples are affected by the new correction. 

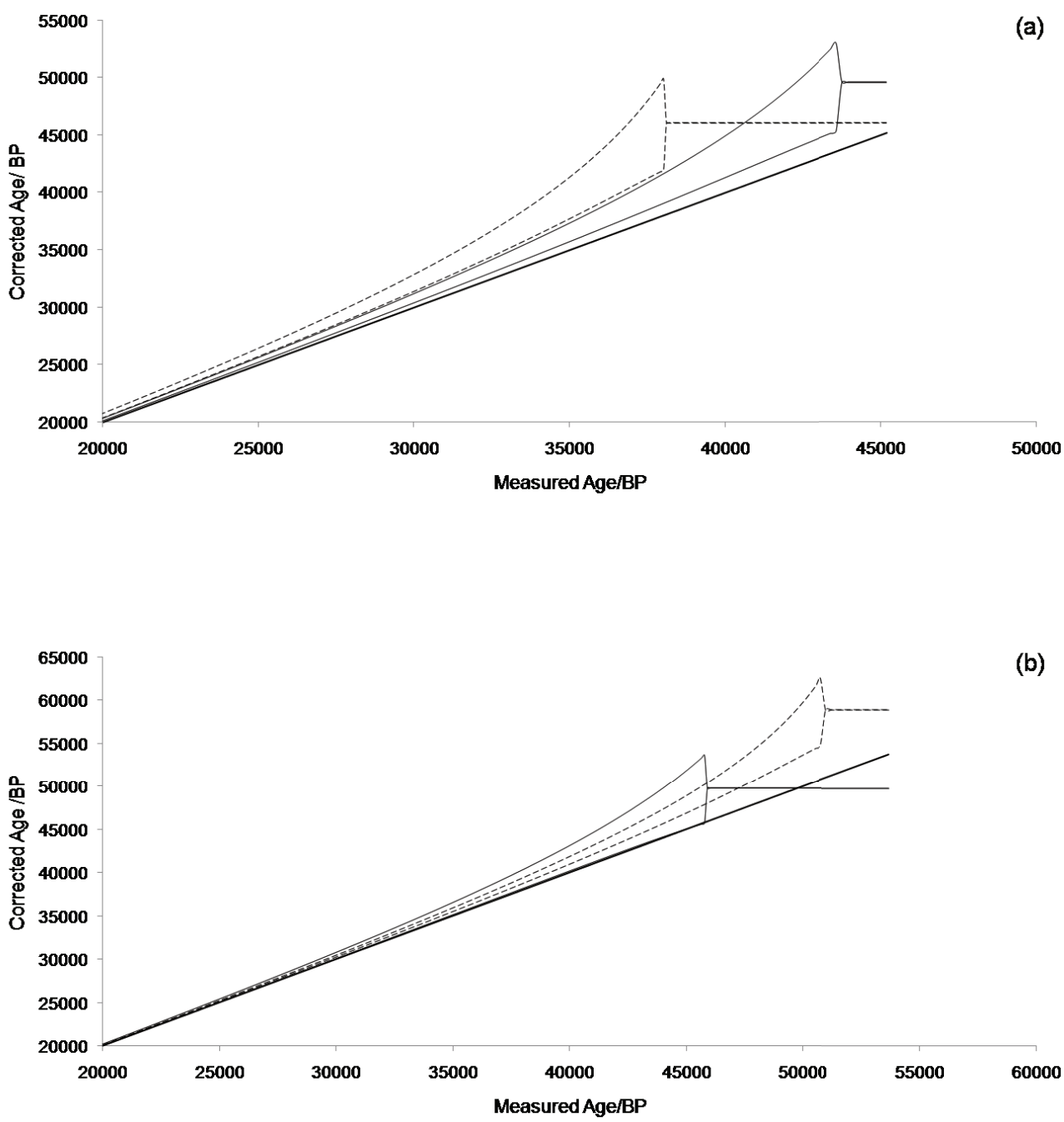

Figure 5 Comparison of the effect that the existing (dashed line) and proposed (thin solid line) correction models have on the corrected age of (a) $5 \mathrm{mg}$ collagen and (b) $40 \mathrm{mg}$ collagen. One-sigma error limits are shown and a horizontal line denotes the infinite age. The dark solid line indicates the age if neither combustion or pretreatment corrections are applied. A $44 \%$ collagen carbon content, a combustion yield of $1.8 \mathrm{mg}$ carbon and a measurement error of 0.0002 have been assumed.

Table 3 Comparison of samples from the Middle-Upper Palaeolithic Project after correction with the existing and new corrections.

\begin{tabular}{llcclc}
\hline OxA- & Site & $\begin{array}{l}\text { Collagen } \\
\text { yield }(\mathrm{mg})\end{array}$ & $\% \mathrm{C}$ & $\begin{array}{l}\text { Age after existing } \\
\text { correction (BP) }\end{array}$ & $\begin{array}{l}\text { Age after new } \\
\text { correction (BP) }\end{array}$ \\
\hline X-2286-9 & Mandrin & 4.09 & 44.5 & $>39,200$ & $38,900 \pm 1100$ \\
X-2286-10 & Mandrin & 5.34 & 45.5 & $42,300 \pm 2400$ & $38,500 \pm 1000$ \\
X-2314-43 & Labeko Koba & 8.23 & 43.4 & $38,000 \pm 1000$ & $36,500 \pm 750$ \\
21,777 & Labeko Koba & 17.83 & 38.2 & $38,050 \pm 550$ & $37,700 \pm 900$ \\
21,696 & Mandrin & 19.71 & 41.1 & $>56,100$ & $>49,900$ \\
21,684 & Mandrin & 38.7 & 42.6 & $37,250 \pm 400$ & $37,400 \pm 900$ \\
\hline
\end{tabular}




\section{CONCLUSION}

A new background correction has been derived for the combustion and ultrafiltration protocols applied at ORAU. These corrections will be applied to all ${ }^{14} \mathrm{C}$ dates undertaken as part of the Middle-Upper Palaeolithic Project (NERC grant NE/D014077/1), and all samples dated from January 2010 (OxA-21508 onwards). The combustion background sets a maximum age of 54,000 BP for all samples combusted within the CHN analyzer. The ultrafiltration pretreatment adds an extra background term resulting in a background age of 49,900 BP for bone and allows the minimum collagen size required to be lowered from its present 10 -mg limit to $5 \mathrm{mg}$. It does not significantly alter the age of the majority of bones dated at ORAU, but is, however, crucial for the identification of the point at which the date is regarded as infinite for the smallest $(<10 \mathrm{mg})$ and largest $(>30 \mathrm{mg})$ collagen samples. These findings demonstrate the importance of such work when quoting finite ages of samples close to the limit of ${ }^{14} \mathrm{C}$ detection.

\section{ACKNOWLEDGMENTS}

Thanks are extended to all of the staff at ORAU, especially Fiona Brock, Angela Bowles, Jane Davies, Barbara Emery and Christine Tompkins, and to Duane Froese (Alberta), Alvaro Arrizabalaga (Vitoria, Spain), Ludovic Slimak (Toulouse), and Greg Hodgins (Arizona) for providing the bones. R W is funded by a tied-NERC studentship (grant NE/D014077/1). The Natural Environment Research Council (NERC grant NE/D014077/1) are thanked for funding of the Middle to Upper Paleolithic transition project. Marian Scott and Richard Staff read an earlier version of this work, and their comments are greatly appreciated. Two anonymous reviewers are also thanked for their valuable remarks. Any errors are of course our own.

\section{REFERENCES}

Brock F, Bronk Ramsey C, Higham TFG. 2007. Quality assurance of ultrafiltered bone dating. Radiocarbon 49(2):187-92.

Brock F, Higham TFG, Ditchfield P, Bronk Ramsey C. 2010. Current pretreatment methods for AMS radiocarbon dating at the Oxford Radiocarbon Accelerator Unit (ORAU). Radiocarbon 52(1):103-12.

Bronk Ramsey C. 1995. Radiocarbon calibration and analysis of stratigraphy: the OxCal program. Radiocarbon 37(2):425-30.

Bronk Ramsey C. 2001. Development of the radiocarbon calibration program. Radiocarbon 43(2A):355-63.

Bronk Ramsey C, Higham T, Bowles A, Hedges R. 2004a. Improvements to the pretreatment of bone at Oxford. Radiocarbon 46(1):155-63.

Bronk Ramsey C, Higham TFG, Leach P. 2004b. Towards high-precision AMS: progress and limitations. Radiocarbon 46(1):17-24.

Brown TA, Nelson DE, Vogel JS, Southon JR. 1988. Improved collagen extraction by the modified Longin method. Radiocarbon 30(2):171-7.

de Rooij M, van der Plicht J, Meijer HA. 2008. Sample dilution for AMS ${ }^{14} \mathrm{C}$ analysis of small samples (20 $150 \mu \mathrm{g} \mathrm{C)}$. Radiocarbon 50(3):413-36.

Dee M, Bronk Ramsey C. 2000. Refinement of graphite target production at ORAU. Nuclear Instruments and Methods in Physics Research B 172(1-4):449-53.
Gupta SK, Polach HA. 1985. Radiocarbon Dating Practices at ANU. Handbook, Radiocarbon Dating laboratory Research School of Pacific Studies, ANU. Canberra. $173 \mathrm{p}$.

Higham TFG, Jacobi RM, Bronk Ramsey C. 2006a. AMS radiocarbon dating of ancient bone using ultrafiltration. Radiocarbon 48(2):179-95.

Higham T, Bronk Ramsey C, Karavanic I, Smith FH, Trinkaus E. 2006b. Revised direct radiocarbon dating of the Vindija $\mathrm{G}_{1}$ Upper Paleolithic Neandertals. Proceedings of the National Academy of Sciences of the United States of America 103(3):553-7.

Hüls CM, Grootes PM, Nadeau M-J. 2009. Ultrafiltration: Boon or bane? Radiocarbon 51(2):613-26.

Jacobi RM, Higham TFG, Bronk Ramsey C. 2006. AMS radiocarbon dating of Middle and Upper Palaeolithic bone in the British Isles: improved reliability using ultrafiltration. Journal of Quaternary Science 21(5): 557-73.

Jacobi RM, Higham TFG. 2008. The "Red Lady" ages gracefully: new ultrafiltration AMS determinations from Paviland. Journal of Human Evolution 55(5): 898-907.

Jacobi RM, Higham TFG. 2009. The early Lateglacial recolonization of Britain: new radiocarbon evidence from Gough's Cave. Quaternary Science Reviews 28(19-20):1895-913. 
Jöris O, Álavarez Fernández A, Weninger B. 2003. Radiocarbon evidence of the Middle to Upper Palaeolithic transition in southwestern Europe. Trabajos de Prehistoria 60(2):15-38.

Kirner DL, Taylor RE, Southon JR. 1995. Reduction in backgrounds of microsamples for AMS ${ }^{14} \mathrm{C}$ dating radiocarbon. Radiocarbon 37(2):697-704.

Staff R, Brock F, Chivall D, Ditchfield P, Humm M, Leach P, Bronk Ramsey C. 2009. Method development for very small mass samples at the Oxford Radiocarbon Accelerator Unit [abstract \#92]. 20th International Radiocarbon Conference, 31 May-5 June 2009, Kona, Hawaii, USA.

Tisnérat-Laborde N, Valladas H, Kaltnecker E, Arnold M. 2003. AMS radiocarbon dating of bones at LSCE.
Radiocarbon 45(3):409-19.

van Klinken GJ. 1999. Bone collagen quality indicators for palaeodietary and radiocarbon measurements. Journal of Archaeological Science 26(6):687-95.

Vogel JS, Nelson DE, Southon J. 1987. ${ }^{14} \mathrm{C}$ background levels in an AMS system. Radiocarbon 29(3):323-33.

Waterbolk HT. 1971. Working with radiocarbon dates. Proceedings of the Prehistoric Society 37:15-33.

Westgate JA, Preece SJ, Froese DG, Pearce NJG, Roberts RG, Demuro M, Hart WK, Perkins W. 2008. Changing ideas on the identity and stratigraphic significance of the Sheep Creek tephra beds in Alaska and the Yukon Territory, northwestern North America. Quaternary International 178(1):183-209. 